\title{
GRACIELA Y MEDEA, MUJERES EN EL TEATRO: DE EURÍPIDES A GARCÍA MÁRQUEZ
}

\author{
ROCÍO VALERA SÁNCHEZ \\ Universidad de Murcia \\ rocio.valera@um.es \\ ORCID: 0000-0002-7585-8656
}

\section{RESUMEN}

El presente trabajo aborda un estudio literario de carácter comparativo de Diatriba de amor contra un hombre sentado, única pieza teatral de García Márquez, en su relación con Medea de Eurípides. Nos centraremos principalmente en estudiar las similitudes y diferencias que caracterizan a las heroínas de cada obra, Graciela y Medea, la evolución que presentan como personajes y la fuerza que poseen como figuras femeninas. Asimismo, estudiaremos la reelaboración y adaptación que hay del mito de Grecia a Hispanoamérica.

En Diatriba encontraremos a una Medea reencarnada en Graciela, una mujer del Caribe que retoma las riendas de su vida, rompiendo con los roles masculinos, y abandona todo en pos de su libertad individual.

PALABRAS CLAVE: Medea, Eurípides, Diatriba de amor contra un hombre sentado, García Márquez.

\section{GRACIELA AND MEDEA, WOMEN IN THE THEATER: FROM EURIPIDES TO GARCÍA MÁRQUEZ}

\section{ABSTRACT}

This project concerns a comparative literary study of Diatriba de amor contra un hombre sentado, García Márquez's first theatrical production, and its relation to Medea by Euripides. We will study, firstly, the similarities and differences which characterize the heroines of both masterpieces, Graciela and Medea, the evolution which they present as characters and the strength they have as female characters. At the same time, we will study how the myth is reconstructing and adapted from Greece to Latin America.

In Diatriba we can find Medea reincarnated as Graciela, a Caribbean woman who takes up her life, breaks with the male roles and drops out everything because of her freedom.

KEYWORDS: Medea, Euripides, Diatriba de amor contra un hombre sentado, García Márquez.

\section{INTRODUCCIÓN}

\subsection{Medea}

Para hablar del teatro de Eurípides es necesario hablar de su propio pensamiento, ya que el tragediógrafo, inserto dentro de la corriente de los sofistas, ${ }^{1}$ se aleja de

\footnotetext{
${ }^{1}$ Seguimos a los estudiosos que relacionan a Eurípides con la sofística, aunque hay otros que discrepan respecto a esta relación. Cf. Campos Daroca, García González, López Cruces y Romero Mariscal (2007).
} 
la idea tradicional que defiende la actuación del individuo según el nómos, según la costumbre, tanto en el plano religioso como en el político. De este modo, podríamos ver en Eurípides la noción de que el individuo debe actuar bajo sus propias normas y modo de pensar. Como ha señalado Herreras,

tanto héroes como dioses forman parte de una crisis religiosa y social. Eurípides acaba aportando un moralismo basado en la conciencia del hombre. Moralismo de base, si se quiere, ya que en sus personajes la razón establece unas normas de conducta fundadas en la conciencia del mismo. (Herreras 2012: 167)

Todo este pensamiento lo observamos precisamente en Medea, donde Eurípides nos muestra a una heroína que lucha por dejar a un lado la humillación causada por Jasón y que muestra al mundo cómo ha vengado su ultraje castigándole para encontrar su razón de ser, su sitio en el mundo conforme a su propio pensamiento. A través de Medea, Eurípides indaga en el ser humano que se consume y disputa una lucha interna entre la pasión y la razón (Lesky 2001: 275, Miranda Cancela 2005: 70). Como ha señalado Lesky (2001: 257), «por toda la obra del poeta discurre una lucha incesante, una búsqueda apasionada [...]» y en ella toda la tradición pierde gran parte de su valor a la hora de enfocar algún problema. Los dioses y su posición en la religión y el pensamiento tradicional ya no tendrán una función tan primordial en un mundo donde el hombre se define como ser pensante capaz de decidir por sí mismo.

\subsection{Diatriba de amor contra un hombre sentado ${ }^{2}$}

Los personajes femeninos ocupan gran parte de la obra de Gabriel García Márquez y se convierten en numerosas ocasiones en sus protagonistas, como ocurre en obras como La cándida Eréndira, Los funerales de Mamá Grande, Cien años de soledad o Diatriba de amor contra un hombre sentado. Las mujeres de estas obras se insertan en un ambiente en el que asumen un rol reducido a la esfera privada, al hogar y a la maternidad, o en un ambiente en el que rompen con los roles masculinos para definirse como mujeres poderosas que toman conciencia de su autonomía, perfiladas, de este modo, dentro de una sociedad patriarcal. ${ }^{3}$

${ }^{2}$ La relación de García Márquez con los trágicos griegos es importante para entender gran parte de su obra literaria. Esta relación es mencionada por él mismo en numerosas entrevistas y en Vivir para contarla (2015: 360), donde apunta al descubrimiento y la lectura constante que él hizo de los clásicos grecolatinos y la influencia que ejercieron sobre él, especialmente Sófocles con Edipo rey.

${ }^{3}$ De esta misma manera se entendía el personaje femenino en la Antigüedad, donde cualquier desvío en el camino recto suponía un acto de rebeldía. Esteban Santos (2005: 63-93) realiza un catálogo de mujeres de la mitología griega, a las cuales divide entre mujeres víctimas y mujeres terribles. Entre las muchas clasificaciones que lleva a cabo dentro del segundo grupo, el último es el que más nos interesa, pues es ahí donde cataloga a las mujeres justicieras y vengativas, donde se encuentran Medea, Electra, Hécuba, etc. Esteban Santos las define como «las que se alzan asesinas contra quienes les ha hecho profundo agravio e injusticia, contra el varón casi siempre» (2005: 70). No obstante, tenemos que dejar claro que, aunque encontremos similitudes entre Graciela y Medea, hay un aspecto que las diferencia y en cierta medida también las distancia: la 
Precisamente, el personaje de Graciela en Diatriba es el de una mujer subordinada a su marido; su vida y su identidad están determinadas por el hombre, y se ciñe a los roles que la sociedad le asigna. Como ha señalado Medina Cano,

Graciela, en su monólogo, deconstruye el rol femenino, hace una evaluación de su historia personal y renuncia a su papel como esposa por una vida mejor y más digna, pone en entredicho el juego de apariencias, los valores y los roles (de esposa y madre) que la sociedad le ha designado como única opción, las posibilidades que la sociedad le niega y las únicas opciones que le ofrece. (Medina Cano 2005: 1)

\section{CARACTERÍSTICAS COMUNES A LAS DOS PROTAGONISTAS}

\subsection{Arrepentimiento por dejar la casa paterna y maldición de los hijos y el marido}

Por un lado, Graciela y Medea guardan un estrecho paralelismo como mujeres arrepentidas por haber abandonado la casa paterna, a la que traicionan para casarse con unos esposos que no las quieren y las han despreciado.

Dice la nodriza en los versos 34-39 de Medea:4

Y en su infortunio aprende la mísera qué bueno es el no partir nunca de la paterna tierra. Y aborrece a sus hijos y en verlos no se goza; temo incluso que algún raro proyecto trame. Pues duro es su carácter y soportar no puede que nadie la maltrate.

Más adelante, la propia Medea apunta a este hecho evocando a su madre y a su hermano, a los que traicionó (vv. 253-258):

Tú tienes aquí tu ciudad, la casa de tu padre, la ilusión de la vida, la compañía de tus amigos; pero yo, estando sola y sin ciudad, sufro las injurias de mi marido, cogida como botín desde un país bárbaro, sin tener madre, ni hermano, ni pariente adonde ir a anclar alejándome de mi desdicha. ${ }^{5}$

Una idea similar se ve en el monólogo de Graciela, en el que se muestra arrepentida por haberse ido con su marido años atrás (García Márquez 1995: 2324), y en el que evoca, al igual que Medea, ${ }^{6}$ a su madre, contra la que se rebeló para casarse con el hombre que la ha humillado:

brutalidad que caracteriza a Medea por matar a sus hijos y en lo terrible que esto convierte al personaje.

${ }^{4}$ Las traducciones de la Medea de Eurípides corresponden todas a López Férez (2005).

${ }^{5}$ Aquí vemos el motivo de la princesa que traiciona a su familia por amor hacia un extranjero, como ocurre con otras mujeres de la mitología como Hipodamía o Ariadna. Como señala García Gual (1971: 85-107), la princesa ayuda al héroe a superar sus pruebas más difíciles y Medea es un ejemplo de ello. Más tarde se fuga con él por amor, e incluso mata a su hermano para tomar ventaja en la huida. Pero, cuando el héroe ya no necesita a la joven muchacha, se deshace de ella.

${ }^{6}$ La diferencia entre Medea y Graciela en este punto es que Medea sí que huye de la casa paterna y se va con Jasón por el profundo amor que siente hacia él. En el caso de Graciela, en cambio, la 
Ganas me dan de romperme la cabeza contra las paredes, nada más de pensar que mi madre será la única que no vendrá esta noche. La primera que merecía estar. [...] Otra habría sido mi suerte si hubiera heredado su virtud de ver las cosas antes que sucedieran. (García Márquez 1995: 23-24)

Y más adelante vuelve a decir (1995: 26): «Si me emperré contigo desde el principio fue solo para contrariar a mi madre [...]». Y luego vuelve a lamentarse recordando aquellos viejos tiempos (1995: 27): «Quedamos parejos: tú repudiado por tus padres y yo por los míos. Pero felices por lo que no teníamos. Al revés de ahora, que nos sobra de todo menos el amor».

Por otro lado, otra característica que perfila a nuestras protagonistas es que maldicen el fruto de su matrimonio, sus hijos, a la vez que maldicen al marido. Su actitud hacia los hijos no es por un odio en sí mismo hacia ellos, pues no han cometido ningún acto impío contra su madre, sino por un odio hacia el marido que pagan con los hijos:

-Medea (vv. 112-114): «[...] ¡Malditos muráis, pues nacisteis de mí, una madre funesta, y perezca también vuestro padre y la casa con él!»

-Graciela (García Márquez 1995: 12): «Y todavía debo agradecerle que me haya dado todo lo necesario para gozar de mi estupidez, día por día, durante veinticinco años. Todo, hasta un hijo seductor y holgazán, y tan hijo de puta como su padre».

No obstante, hay aquí varios aspectos que diferenciar entre Medea y Graciela. Cada vez que Graciela habla de su hijo, muestra una actitud muy crítica y contundente hacia él, comparándolo constantemente con el padre. Quizás, incluso, podemos decir que lo aborrece, ya que es la viva imagen de un marido que no se porta bien con ella. El caso de Medea es diferente, ya que ella se ve movida por sentimientos que chocan entre sí: la razón y la pasión la llevan a un debate interno antes de perpetrar el crimen. Como ha señalado Esteban Santos (2005: 74), Medea es consciente de que debe asesinar a sus hijos y de que no hay alternativa, pero es para ella un acto terrible y doloroso, pues los ama profundamente.

\subsection{Desencadenante trágico: la aparición de una mujer más joven en el contexto de la efeméride de unas nupcias}

Lo que lleva a las heroínas a terminar de aborrecer al marido y la vida que hasta ahora han llevado bajo su yugo es la aparición de una mujer más joven que ellas y el modo en que proceden los maridos.

Por un lado, Jasón utiliza como argumento el hecho de que él actúa de acuerdo con lo que cree que es mejor para su familia. Según él, decide casarse con la hija de Creonte para dar un mejor estatus social a su familia y poder cuidar mejor de ellos (vv. 550 ss.). Pero con su decisión no mejora la condición familiar,

protagonista se marcha con su marido más por contrariar a su madre que por que verdaderamente quiera a su marido, hecho que la diferencia profundamente de Medea. 
sino que rompe la unión conyugal con Medea, a la que priva del oíkos y deja en una situación desesperante. Como ha señalado Morenilla,

Medea [...] ha sido privada de su honor, del reconocimiento que se le debe, que en el caso de una mujer se objetiva en el lecho, que representa su posición en la casa y, por ello, en la sociedad. (Morenilla 2006: 469)

En el caso de Diatriba, el marido de Graciela actúa a sabiendas de que está actuando mal, pues es infiel a su mujer y no disimula ante ella. Él no pretende mejorar su estatus social ni poner facilidades a su familia, porque ya posee estas condiciones. ${ }^{7}$ Además, hay una diferencia notable entre Jasón y el marido de Graciela, ya que mientras que Jasón toma parte en la obra y se defiende de las acusaciones y los reproches de Medea, el marido de Graciela, por su parte, no habla en ningún momento, pues es un personaje silente. Ambos personajes se muestran desagradables con sus mujeres, pero de maneras diferentes: el primero de ellos mediante la palabra, el segundo con el silencio, también igual de hiriente.

Así, la manera de actuar de estos desencadenará la rebelión de las dos protagonistas. Ambas lo afirman con su actitud en las obras y también con sus propias palabras. Dice Medea (vv. 263-266):

Pues una mujer normalmente está llena de miedo y es cobarde para contemplar la pelea y el hierro, mas, cuando resulta injuriada en lo referente a su lecho, no hay otro espíritu más sanguinario.

Y también dice Graciela en tono irónico y dañino a propósito de la fiesta en la que celebran sus bodas de plata:

Y vendrá ella, por supuesto, ella primero de todos. ¿Qué creías? ¿Que me iba a someter a la humillación de no invitarla? ¡Ja, ja! Si nos ha hecho el honor en otros tantos aniversarios, infaustos o gloriosos, no veo por qué no iba a estar en el más memorable de todos: el último. (García Márquez 1995: 15-16)

No obstante, la venganza que perpetran las heroínas es diferente y ello hace distintas las obras. El objetivo principal de Medea es vengarse de Jasón para mantener su honra, que no es el mismo en Graciela, ya que esta última lo que quiere es pronunciar contra él un largo reproche y mostrar su lugar en el mundo. Tras años de infidelidad, Graciela rompe con todo y le muestra a su marido que ahora es ella quien va a marcar su propio camino. Si al final Graciela mata a su marido, será de manera espontánea, decidiéndolo en el último momento y casi como una travesura. En el caso de Medea, el asesinato de los hijos está pensado y calculado, ya que ella piensa a lo largo de la obra cómo puede vengarse de Jasón, haciéndole pagar tanto daño. Como ha señalado Esteban Santos,

\footnotetext{
${ }^{7}$ De hecho, García Márquez pretende mostrar en la obra una crítica a la sociedad alta del Caribe en aquella época a través del estatus social que representan Graciela y su marido.
} 
El horrendo asesinato de sus hijos es para ella dolorosísimo. Pero lo ve irremediable, según los impulsos de su carácter fuerte y soberbio, y como único medio de lavar su honra mancillada, lo que para ella está por encima de todo. Lo justifica además como preferible a que los niños se vean expuestos a una cruel venganza por parte de los corintios tras el regicidio. De modo que llega a ello conscientemente y no ofuscada su razón por la locura. (Esteban Santos 2005: 74)

Por otro lado, las dos jóvenes amantes aparecen como intrusas y destructoras, junto con el marido, del lecho conyugal. Además, la aparición de las muchachas en las obras se hace efectiva en el momento de celebración de un acto matrimonial, ya les afecte este acto de manera directa o indirecta. En el caso de Medea, el rito matrimonial se celebrará entre Glauce y Jasón muy pronto, lo que desencadena la ira de Medea. En el caso de Diatriba, Graciela y su marido acaban de festejar sus bodas de plata y la amante se encuentra entre los invitados. Es en ese momento cuando Graciela desata la diatriba contra su marido silente e inmóvil ante el periódico.

\subsection{La promesa del marido de un matrimonio feliz y el incumplimiento de esta promesa}

Tanto Jasón como el marido de Graciela formulan a sus esposas una promesa matrimonial, pero finalmente la rompen y ellas quedan desengañadas. Jasón viola los juramentos sociales, religiosos y familiares, lo que conlleva la ruptura del núcleo familiar ( $c f$. López Galocha 1995: 122) y el consecuente castigo por el delito tan grave que Jasón ha cometido (romper los sagrados juramentos para mejorar su situación político-social). También el marido de Graciela rompe el compromiso matrimonial cuando le es infiel a su esposa, pero su acto alcanza un nivel de ultraje menor para Graciela que en el caso de Medea, debido al contexto social de la época en el que una mujer griega quedaba totalmente marginada si era repudiada por el marido.

Graciela pierde así veinticinco años de su vida por un hombre que realmente no merece la pena, igual que Medea, que ha sido capaz incluso de matar a su hermano por Jasón. Ambas protagonistas han dejado y dado todo por sus maridos, y han renunciado a su casa paterna por ellos. ${ }^{8}$ Como Medea, que ayuda a Jasón a cumplir las pruebas impuestas por Eetes y que escapa con él sabiendo que su familia no la perdonará, Graciela huye una noche con su futuro marido sabiendo que será repudiada por su familia. Y por esto ellas ahora se sienten ultrajadas y traicionadas, de manera que se lo reprochan todo a sus maridos. Así dice Graciela:

\footnotetext{
${ }^{8}$ No obstante, como ya mencionamos anteriormente, Medea abandona la casa paterna por amor y Graciela por contrariar a su madre. Además, otra diferencia que hay entre las dos protagonistas es que Medea, movida por el amor que siente hacia Jasón, mata su hermano, mientras que Graciela simplemente huye, sin perpetrar la muerte de ningún familiar.
} 
No tenía nada, pero renuncié a todo por ti. [...] Claro que nunca lo valoraste como una inmolación. ¡Qué va! Ni te enteraste siquiera. ¿Sabes por qué? Porque toda tu vida has sido inferior a tu propia suerte. En cambio yo no tengo quien me cargue la cruz, porque yo misma me serví mi láudano con cucharitas de oro. (García Márquez 1995: 25)

Por su parte, Medea le dice a Jasón (vv. 483 ss.):

Yo misma, tras traicionar a mi padre y mi palacio, vine contigo a la peliótide Yolco, con más resolución que cordura. Y logré eliminar a Pelias del modo más doloroso de morir, por mano de sus propias hijas, y destruí todo su hogar. Y, habiendo recibido ese trato de parte nuestra, joh el peor de los hombres!, nos has traicionado y has contraído nuevo matrimonio, aunque tenías hijos.

Pero los maridos encienden aún más la cólera de sus esposas al decirles que no es a ellas a quienes tienen que agradecer sus éxitos. Jasón le dice a Medea que no fue gracias a ella sino a Cipris por quien salió exitoso de su viaje y que esta, por la ayuda que le pudo prestar, ya está recompensada (vv. 524 ss.):

\begin{abstract}
Yo, toda vez que exageras en demasía tus servicios, pienso que Cipris fue respecto de mi viaje por mar la única salvadora entre los dioses y los hombres. Tienes fina inteligencia, pero te resulta odioso explicar que Eros te forzó, con sus dardos inevitables, a salvar mi vida. Mas no lo expondré con demasiada exactitud, pues de cualquier forma que me hayas ayudado, no está mal. Sin embargo, por haberme salvado, has recibido más de lo que diste $[\ldots]$.
\end{abstract}

También la actitud del marido de Graciela se muestra muy similar a la de Jasón. La diferencia entre uno y otro es que el marido de Graciela no habla directamente. Lo que conocemos de él, lo que dice y piensa, es a través del parlamento de Graciela, de modo que tenemos una visión subjetiva de él. Dice Graciela:

¿Qué esperas, que me precipite en tus brazos para agradecerte lo que has hecho por mí? ¿Que te rinda el tributo de mi gratitud eterna por haberme cubierto de oro y gloria? (García Márquez 1995: 17)

Además, los maridos atacan a sus esposas mostrando un desprecio hacia el género femenino. Jasón le dice a Medea que las mujeres se ofenden fácilmente y que el mundo sería mejor si no existieran (vv. 569 ss.):

Mas las mujeres habéis llegado al extremo de que, si vuestro matrimonio marcha bien, pensáis que lo tenéis todo, pero si acontece algún infortunio en lo referente a vuestro lecho, lo más convincente y lo más hermoso lo tomáis por lo más hostil. En verdad, sería necesario que los mortales engendrasen hijos de alguna forma distinta y que no existiera el linaje femenil. De ese modo los hombres no tendrían ninguna desgracia. ${ }^{9}$

\footnotetext{
${ }^{9}$ El nivel de soberbia al que Jasón llega se muestra también en los versos 573 ss., donde dice que debería existir otra forma de engendrar hijos para poder prescindir de la raza de las mujeres $\left(\theta \tilde{\eta} \lambda v \delta^{\prime}\right.$ oủK $\varepsilon i ̃ v \alpha \iota ~ \gamma \varepsilon ́ v o s$, v. 574). Este concepto de la raza de las mujeres en la cultura griega, tan
} 
Y Graciela también habla a propósito de su marido (1995: 25): «Y todavía tienes el descaro de decirme que la vejez me está volviendo celosa».

De este modo vemos cómo Jasón y el marido de Graciela se configuran como maridos traidores ${ }^{10}$ y egoístas desagradecidos que abandonan a sus esposas y las humillan. Se muestran altaneros y no reconocen la ayuda que otrora ellas pudieron prestarles. En el caso de Jasón, además, este se muestra cínico al decirle a Medea que es ella quien debería agradecerle, pues vive en tierras griegas siendo bárbara y es conocida entre los griegos gracias a él (vv. 536 ss.).

\subsection{La falta de libertad moral y personal de las protagonistas frente a la total autonomía del marido.}

Tanto Diatriba como Medea se insertan dentro de una sociedad patriarcal en la que la mujer, como ya hemos comentado, está totalmente relegada a la esfera familiar y conyugal. Como ha señalado Medina Cano,

La división del trabajo de las sociedades patriarcales le otorgaba el mundo exterior al hombre, y el hogar y la procreación a la mujer. La identidad del hombre se consolidaba en su relación con el mundo exterior, en la apropiación que realizaba de él, en su actividad de dominio y control. [...] La mujer [...] estaba ausente del mundo exterior, sus tareas no excedían el ámbito de lo doméstico, su voz no se hacía oír en el mundo que tradicionalmente le pertenecía al hombre (en el mundo de la política, de la historia, de la ciencia). (Medina Cano 2005: 19)

Nuestras heroínas son las que deciden romper con esa sociedad patriarcal y definirse, a partir de ese momento, como mujeres libres. Importantes son, en este punto, los dos monólogos que pronuncian Graciela y Medea, hartas de la sociedad que les asigna un fin determinado como mujeres: ser esposas y madres. Cada una de ellas rechaza la situación social que les ha tocado vivir como mujeres subordinadas al hombre, sin tener que quejarse, callando y contentando al marido. Así, Medea hace en su parlamento hacia el coro de mujeres corintias una fuerte crítica al desajuste social entre hombres y mujeres, en el que estas últimas son las más desfavorecidas (vv. 230 ss.):

De todos los seres animados y dotados de pensamiento las mujeres somos el más desdichado. Pues, en primer lugar, tenemos que comprar un marido con excesivo gasto de dinero y conseguir un dueño de nuestro cuerpo, pues esta es una desgracia más dolorosa aún. Y el combate supremo consiste en conseguirlo malo o bueno. Las separaciones no reportan buena fama a las mujeres, y no es posible repudiar al esposo. Cuando una ha arribado a nuevas costumbres y leyes menester es que sea adivina, sin haberlo aprendido en casa, de cómo tratará mejor a su compañero de lecho. Y si logramos cumplir eso bien y nuestro marido habita con nosotras sin imponernos el yugo por la fuerza, envidiable es

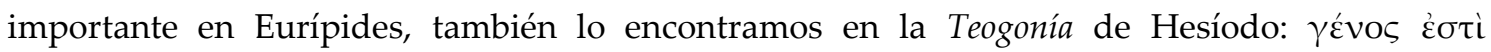
$\gamma v v \alpha \iota \kappa \tilde{\omega} v \theta \eta \lambda v \tau \varepsilon \varrho \alpha ́ \omega v$ (Th. 590-591).

${ }^{10}$ Además, Jasón se muestra ambicioso, pues su propósito es ascender en la escala social, aspecto en el que difiere con el marido de Graciela. 
nuestra vida. Pero, si no, menester es morir. Un hombre, en cambio, cuando se hastía de convivir con los de dentro, yéndose fuera, calma el fastidio de su corazón, tras dirigirse a casa de un amigo o de uno de su edad. Para nosotras, al contrario, es forzoso dirigir la mirada a un solo hombre. Dicen que nosotras pasamos en nuestros hogares una vida carente de peligros, mientras que ellos combaten con la lanza. Pero razonan con torpeza. Que tres veces preferiría yo permanecer junto al escudo, antes que tener un solo parto.

Como ha señalado Esteban Santos (2005: 79), «su dolor atroz y su humillación no solo las siente de manera individual, sino también como representante de la mujer en general. Pues no se resigna tampoco a la situación común de inferioridad de la mujer respecto al hombre», y todo ello lo podemos ver en este parlamento.

Graciela, por su parte, habla al final de la obra de todas las cosas de las que está harta respecto a su marido. Aunque no ha dejado de hacerlo a lo largo de todo el monólogo, en esta última parte la tensión dramática es mayor, sobre todo por la repetición incesante de un «no aguanto más». En este parlamento, Graciela se queja de lo mismo que Medea: dedicarse por completo a contentar al marido en pos de su felicidad y no de la propia. Dice Graciela (1995: 72): «Si el matrimonio no puede darme más que honor y seguridad, a la mierda: ya habrá otros modos». Y más adelante dice:

No aguanto más los incordios minúsculos de la felicidad cotidiana. No aguanto más no saber a qué hora se come porque nunca se sabe a qué hora vas a llegar. [...] No aguanto más que cuando llegas seas tan seductor que me tratan a mí como si fuera yo la que llega tarde, o peor, la que no te deja llegar [...]. No aguanto más difamaciones de imbéciles contra mis hombres de letras. [...] No aguanto más el inventario matutino de tus desgracias [...]. (García Márquez 1995: 73-74)

Y en otro momento Graciela reprocha al marido, como Medea se queja a las mujeres corintias, que este pueda salir y entrar del hogar familiar cada vez que le apetezca, mientras que la mujer no puede salir de casa o es cuestionada inquisitoriamente por el marido. Dice:

En cambio, nada los vuelve tan valientes como los celos. Porque el colmo del descaro es ese, que no hay nadie más celoso que un marido infiel. Figúrate. Se pasan la tarde con la otra, y vuelven a casa enloquecidos por saber con quién hablábamos por teléfono. [...] En cambio regresas de tus gatuperios haciendo preguntas con emboscadas, diciendo mentiras para sacar verdades, y tratando de enterarte de paso dónde voy a almorzar, con quién, a qué hora, para saber adónde puedes ir con ella sin tropezarte conmigo. (García Márquez 1995: 51-52)

Así, las cualidades de la esposa perfecta en esta sociedad patriarcal serían la obediencia al marido y la capacidad de sacrificarse por él, así como confiar plena y ciegamente en él (Medina Cano 2005: 18). Hasta el momento, los hombres de las dos obras han gozado de la presencia de estas cualidades en Medea y Graciela, pero, cuando ellas se han visto ultrajadas y abandonadas por sus maridos, han tomado conciencia de cuál era la realidad que las circundaba. Por 
medio de la palabra, del discurso que pronuncian, se liberan del yugo que las oprime para realizarse como mujeres y encontrar su propia libertad. Como ha señalado Medina Cano a propósito de Graciela, pero extensible también a Medea, el monólogo de ambas sería

\begin{abstract}
el resultado de un acto de lucidez, de una revelación, de un cambio en su manera de entender el mundo y su papel como mujer. Graciela es una mujer conocedora de sí misma y de su deseo, es una feminidad autoafirmativa que pone en evidencia en su monólogo su capacidad de decidir, que busca ser autónoma en sus acciones, y que pretende construir su mundo propio y ubicarse en él según su propio arbitrio y no según los dictados ajenos. Su parlamento no es un discurso incoherente y apasionado, es el resultado «de un análisis serio y desgarrador», de un cambio de mentalidad cuando ella logra descifrar el sentido de su infidelidad: es una liberación. (Medina Cano 2005: 12)
\end{abstract}

\title{
3. CONCLUSIONES
}

Medea y Graciela rompen con la vida que llevan hasta ahora para rebelarse contra sus maridos y mostrar su propia voz. Son mujeres que han estado a la sombra y lo han dado todo por sus maridos -incluso escapar de sus casas en contra de sus familias -, hasta que han sido conscientes de sí mismas y han tenido la necesidad de mostrar que tienen un lugar en el mundo. El punto de inflexión para ambas es la intrusión de una nueva mujer en el ámbito marital, destructora del lecho conyugal (bien sea con unas nuevas nupcias, en el caso de Medea, o con una infidelidad, en el caso de Graciela), que les hace ver la falta de libertad moral que tienen como mujeres en una sociedad patriarcal en que los hombres están dotados de absoluta autonomía. Además, ambas, en su rebelión, se encuentran con unos maridos llenos de soberbia y cinismo que no agradecen a sus esposas lo que han hecho por ellos. Finalmente, se vengarán de ellos, aunque de modo diferente: Medea mata a Glauce y a sus hijos para hacer daño a Jasón en un plan premeditado; Graciela, en cambio, mata a su propio marido en un arrebato final, casi como una travesura, algo improvisado en el último momento.

\section{BIBLIOGRAFÍA}

CAMpos Daroca, J., García GonZÁlez, F. J., LÓPEZ Cruces, J. L. y ROMERO MARISCAL, L. P. (2007), Las personas de Eurípides, Amsterdam, Hakkert.

EstebAn SANTOS, A. (2005), «Mujeres terribles (Heroínas de la mitología griega I)», $C F C(G), 15,63-93$.

GARCíA GUAL, C. (1971), «El argonauta Jasón y Medea. Análisis de un mito y su tradición literaria», Habis, 2, 87-107.

GARCíA MÁRQueZ, G. (1995), Diatriba de amor contra un hombre sentado, Barcelona, Grijalbo Mondadori.

GARCíA MÁRQUEZ, G. (2015), Vivir para contarla, Barcelona, Debolsillo. 
HERRERAS, E. (2012), «Eurípides: de la moral pensada a la moral vivida», Contrastes, 17, 159-177.

LESKY, A. (2001), La tragedia griega, Barcelona, Acantilado.

LÓPEZ FÉREZ, J. A. (2005), Eurípides. Tragedias I, Madrid, Cátedra.

LÓPEZ GALOCHA, M. D. (1995), «Estudio socio-político de la Medea de Eurípides», 'Ilu, 0, 117-127.

MEDINA CANO, F. (2005), «Diatriba de amor contra un hombre sentado y el papel de la mujer», Colombia Escritos, 30/30, 46-86.

MirANDA CANCELA, E. (2005), «Medea y la voz del otro en el teatro latinoamericano contemporáneo», Revista de Estudios de Género. La ventana, 22, 69-90.

Morenilla, C. (2006), "Prefigurando a Medea», en Medea: teatro e comunicazione, De MARTINO, F. (ed.), monográfico de Kleos. Estemporaneo di Studi e Testi sulla Fortuna dell'Antico, 11, Bari, Levante, 453-486. 
